\title{
REENACTMENT METHODOLOGIES FOR EVERYDAY LIFE RESEARCH: ART THERAPY INSIGHTS FOR VIDEO ETHNOGRAPHY
}

Sarah Pink (RMIT University and Loughborough University) and Kerstin Leder Mackley (Loughborough University)

Pink, S. and K. Leder Mackley (2014) 'Reenactment Methodologies for Everyday Life Research: Art Therapy Insights for Video Ethnography'Visual Studies 29(2), pp.146-154.

\begin{abstract}
In this article we explore the relationship between arts practice and digital-visualsensory ethnography by suggesting how insights from art therapy and art historical accounts of the neurosciences can inform ethnographic ways of knowing. We argue that such insights offer new ways to respond to methodological challenges related to the ongoingness and unstoppable flow of everyday life.
\end{abstract}

\section{Introduction}

To research the everyday ethnographically we need to be 'in there' and part of the very flow of life that we are researching. Yet simultaneously, we need to order what we find into manageable analytical units so that it will be meaningful in academic literatures that is, in a representational world where the everyday becomes abstracted into categories for scholarly analysis. While this is a simple point, it is often not reflected on everyday life research. It is, nevertheless crucial to account for if we want to understand the relationship between everyday life as lived and everyday life as studied. This tension between flow and representation is reflected in contemporary literatures across cultural studies, anthropology and geography. For instance in the interest in both anthropology and human geography in the non-representational (e.g. Ingold 2011, Thrift 2008), and in the work of everyday life scholars such as Michael Gardiner (2009: 385) and Michael Sheringham (2006: 390) who describe us as already 'immersed' in the everyday. We are therefore challenged to conceptualise the world as ongoing, continually changing and not necessarily something we can slice across and capture. Yet we are also required to represent both what people do and feel, and the environments in which they act, so that we can approach these contexts analytically and communicate our findings to other 
scholars. Thus rather than focusing on the 'flow' itself, scholars of everyday life have used concepts such as 'practices', 'emotions', or 'routines' as analytical entry points to research its events, experiences and temporalities.

Yet this is not the only challenge of the study of everyday life as lived. Another is that much of what matters to people in everyday life is obscured from the 'view' of traditional research methods. For instance, what people do (practices/practical activity), what they feel (emotions/affect), their regularity and temporality (routine), and their situatedness in relation to others (relationships) in their everyday lives is often done at home, in private and/or at times when researchers are not part of their lives. Not only is everyday life continually moving on but significant parts of it are lived by people out of the radar of even their most intimate family members. The practice of art therapy and art historical studies of practice offer ways of accessing and accounting for the world that both transgress the categories of the social sciences and enable routes to these invisible domains. It is to these we turn to seek alternative ways to research and theorise the everyday.

In what follows we explore how we might access such domains of everyday life through in situ encounters with the material, affective, personal and political elements of the everyday as lived and experienced. We examine, as an example, video recordings of research participants reenacting their everyday laundry practices and routines, produced as part of our research in to everyday energy consumption in homes through the activities in the home for which people need to consume energy. In doing so, we discuss how reenactment can offer routes to knowing about everyday life - for both participants and researchers - that would otherwise be inaccessible. We also reflect on the status of the knowledge that reenactments can offer researchers. Reenactment is interesting to single out for this focus precisely because it is a method and approach that is engaged across arts practice and in academic and applied research contexts that seek to change, influence or transform participants, academics, non-academic/public audiences or clients.

\section{The study of reenactments}

The utility of reenactment has been demonstrated across a range of fields in addition to art therapy. For example, reenactment is part of the practice and subject matter of historical studies and popular culture around historical reconstructions (see McCalman and Pickering 2010) and is used in in crime scene reconstructions (Sherwin et al 2007). 
Reenactment of activities (Pink 2004a), retracing routes (Irving 2010), and revisiting localities (e.g. Parkin and Coomber 2009), is increasingly part of visual ethnography practice as are broader engagements with arts practice (e.g. Lammer 2012) and feminist art therapy (Hogan and Pink 2012). Video reenactments provide routes through which to research and collaboratively apprehend, with research participants, areas of everyday life that are 'hidden', never usually spoken about and therefore under-acknowledged and under-researched. These routine, mundane, unspectacular and 'seemingly' insignificant areas of everyday life are part of those practices, rhythms and accomplishments that create a sense of 'feeling right'; participants in our research felt they 'need' to complete them and felt uncomfortable when they have not (Pink and Leder Mackley 2013).

In this article we draw on arts disciplines to advance this discussion by examining the nature and qualities of the knowledge reenactments reveal. We interrogate the status of the knowledge that one can create through such ethnographic explorations. A frequent question concerns how the presence of the researcher and the reconstructed nature of the research event impacts on the possibility of collecting naturalistic data. As we demonstrate, such questions are (at least in this context) misdirected. Because people participating in video research are always performing the role of participants in video research, it is impossible to get beyond that conundrum. Instead, by accounting for this and investigating what it is that we can find out it is possible to make concrete proposals about the nature of the reality from which our knowledge emerges.

Before developing this discussion further, to introduce readers to an example of the research context and encounters we draws on we present a written and photographic description of a video-recorded reenactment of a participant showing Kerstin how she does the laundry.

\section{Performing the laundry / performing knowledge / performing the self}

As part of our research about everyday energy consumption, we ask participants to perform everyday activities while we video record. We are interested in the everyday doing of laundry because it is a dispersed everyday practice through which electricity is needed to power washing machines, dryers, irons and the other domestic technologies that people use while doing laundry (e.g. to play music, have a warm drink or watch television). Doing the laundry might also involve putting on gas or electric powered central heating, a single room heater or other appliance for drying. 
During the reenactments laundry tasks were performed as new for the camera. Yet, participants were tasked to reenact activities as they would 'normally' do them. They interpreted the task of showing us how they did their laundry in different ways, which might for instance be animated, ironic or matter of fact. In the following example Laura showed Kerstin how she did the laundry while discussing this process with Kerstin and responding to questions about how and why she knew and did certain things. Laura's performance of the laundry process is interesting because while it was quite matter-of-fact and undramatic, there seems to underlie it a questioning or critique of some assumed norms about how laundry is done, and opinions about how these can be transgressed. We might consider this as a laundry process which was done as new, however it is referred to here as a reenactment because it was precisely used as a route to reflecting on what is 'normally' done. Moreover when parts of the process were not done within the laundry routine being performed, these were demonstrated so that Kerstin could understand what else was usually done.

Laura began by pointing out that 'today' was rather different from normal as it was when she usually changed the bed sheets. She took Kerstin upstairs to show her where the dirty laundry was usually stored and collected from, in the laundry basket, which she said 'we just shove everything into'. She explained that the plastic tub was usually just inside the laundry basket or on the floor next to it, and when one of them was nearly full 'that's like a load, a full load in the washer. And I just very generally do light washing and dark washing'.

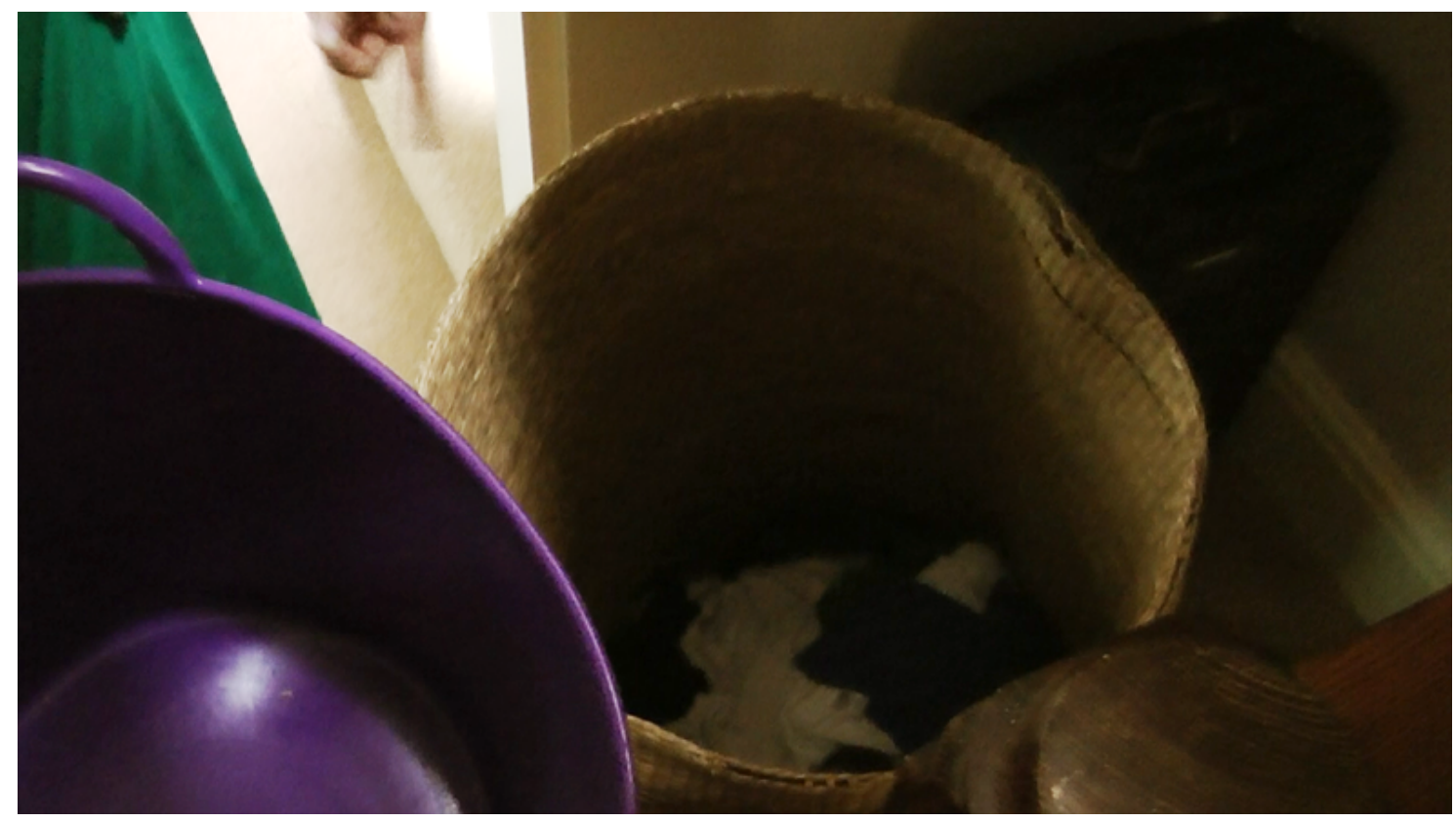




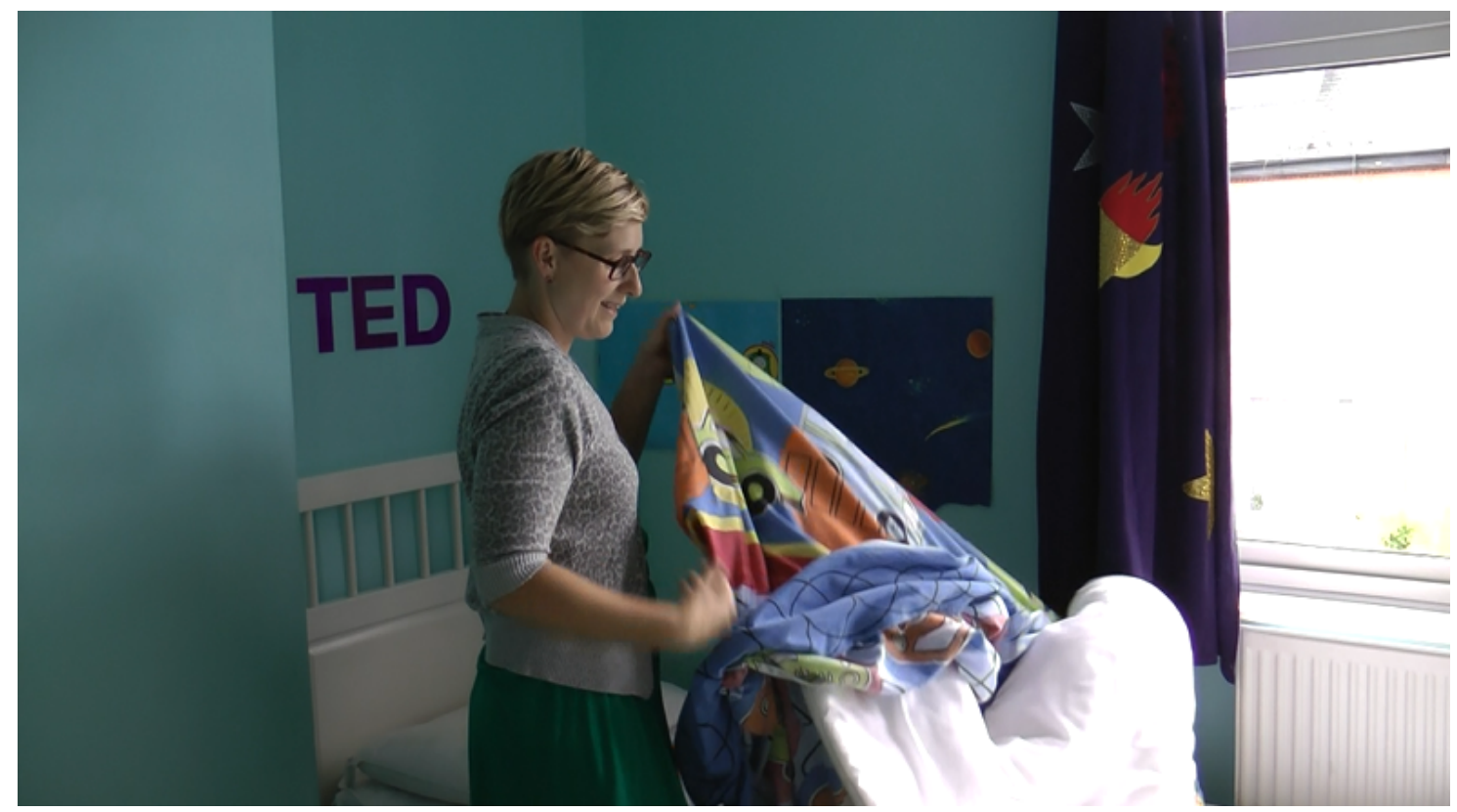

Figure 1. Screenshots: The laundry baskets on the landing, and changing sheets. C) LEEDR, Loughborough University.

Laura took Kerstin to her son's bedroom where she proceeded to strip down the bed, which she said would happen every two weeks or so, given that children were not sweaty, although it had been longer that time because they had been away. When Kerstin asked Laura how she knew that the beds needed changing, she said that 'well you can just kind of tell can't you, it sort of smells a bit fusty and um yeah, a bit, a bit grotty'. In her daughter's room she moved a Barbie salon and princess dress from the bed first, commenting, as she began to take the bed clothing off that: 'slightly controversially I am mixing light washing and dark washing'. However Laura explained that in this instance it did not matter as it was bed linen and she had had the items for some time so knew the colours would not run. As she stepped out of her daughter's room onto the landing, she described how clothing was dried around the home, before proceeding downstairs to the washing machine. Anticipating what she would find, Laura announced that the washing machine was 'filthy', but on opening the door was surprised saying 'oh it's not too bad, I think my mum might have cleaned it'. When Kerstin asked what she meant by it being filthy she explained that it tended to get mouldy around the edge, and that although she did clean it herself, because the washer was used so much it never completely dried out. 

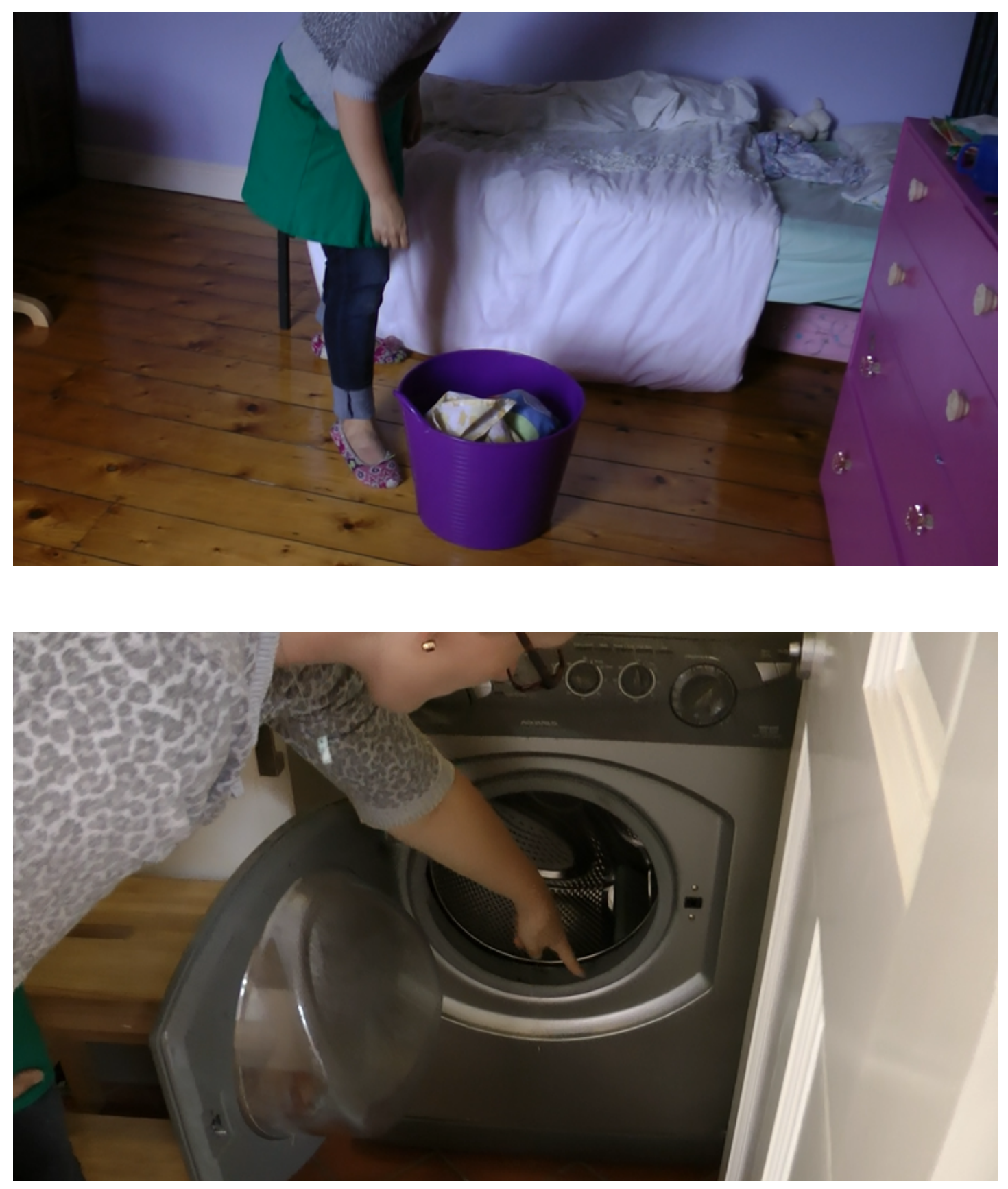

Figure 2. Screenshots: Mixing light and dark, and showing where dirt gathers on the machine. (C) LEEDR, Loughborough University.

Two key issues are raised by this extract. First, Laura sought to show what it felt like to be her doing the laundry and how she maintained a sense of self through the performance of this mundane and routine task. She pointed out ironies, how she made judgments that transgressed the normative things one 'should' do - washing colours and whites together and having 'filthy' parts to her machine. Both were explained, in ways that make her practices feel more normative, yet the performative dimension of this reenactment brought the resistant self to the fore by stating these transgressions. Second, 
we learn about how Laura knew and sensed that things needed to be laundered, and what would make them clean. Partly this involved sensing the 'fustiness' of bedlinen, and partly her learned experience, of what things would look, feel and smell like when they emerged from the machine. Therefore, the reenactment first informs us of how elements of self-identity are performed through everyday tasks. Second it tells us about how embodied and emplaced ways of knowing that are learned incrementally and change over time, are integral to how laundry is done and how identity as a way of knowing can be performed. Ways of knowing about laundry here were indeed embedded in the participants' ongoing and temporal relationship with the material and technological artefacts of the laundry process along with their sensory affordances. Thus, it is evident how doing the laundry at home is contingent on and contributes to both a sense of self and to embodied knowledge.

We next examine how reenactments, and the ways of knowing they produce, enable us to understand the often 'hidden' or obscured dimensions of everyday life, and to situate research in relation to the 'flow' of the everyday. In the next sections we explore two ways of thinking about this question: photo reenactment therapy as developed in the work of Rosy Martin and Jo Spence; and Barbara Stafford's art historical perspective on the relationship between art, representation and the brain sciences.

\section{Ethnography and art therapy: thinking across disciplines}

Re-enactment phototherapy developed by Rosy Martin and Jo Spence in the 1980s is one of a range of related approaches to engaging arts practice for therapeutic work. Martin recounts that on deconstructing how their lives were already represented visually Spence and herself became 'acutely aware of the structured absences and the paucity of representations that were available to us, as middle-aged, working-class women' and 'began the task of reconstruction by creating images that explored the multiplicity of our identities'. As she describes it, their work brought together a range of academic, practice-based and therapeutic skills, in that it was intellectually crafted, through their 'analyses of photographic discourses' and in the literatures of cultural studies and visual culture, as well as their 'experience as practitioners and critics of the links between images and image-making, and notions of conscious and unconscious identities, to which we added therapeutic skills' (Martin 2009). Re-enactment phototherapy has different aims from the uses of video recorded everyday life laundry re-enactments we 
described above. Partly this is because it has its theoretical roots in the cultural studies scholarship of the latter part of the twentieth century. However its aims to create processes of personal transformation for individual clients, and to make personal experience evident in wider political and institutional contexts are particularly pertinent here. As Martin writes:

Phototherapy enables clients themselves to make visible what it is to be subjected to and subject of the discourses within society. Through re-enacting and mapping out being the object of various familial and institutional gazes, including the discourses of education, medicine, law and the media, a complex network of fragmented selves, constructed out of the needs, views, projections and attributions of others, can be made visible (6) (Martin 2009)

The possibilities demonstrated by reenactment phototherapy are instructive and provide significant insights into how using arts practice techniques in research and intervention projects can also enable research participants to gain new levels of self-awareness about their lives and feelings. Such connections are also made, for example in the work of Christina Lammer (e.g. 2012) and Maggie O’Neill (e.g. 2012) who respectively combine ethnographic and arts practices to navigate the relationships between clinical and surgical staff and patients in hospital settings and bring about transformations through arts-based methods with asylum seekers and refugees and homeless people.

There are more broadly correspondences between feminist art therapy and visual ethnography practices, particularly where feminist art therapy 'invites a challenge both to the text-based normative scholarly outcomes and the narrative of academic discourse' (Hogan and Pink 2012: 236) and 'offers routes to interiority that allows the shirting, contingent and transformative nature of the self to become known to the ethnographer and/or to be represented through alternative narrative forms' (Hogan and Pink 2012: 243). There are also existing uses of enactment in visual anthropology research. For instance Andrew Irving's creative research practice involves asking participants reenact, photograph and narrate the routes they took to the clinic on the day they received their HIV diagnosis (e.g. Irving 2010). His work produces very powerful narratives in which the material physical, sensory environment, the affective and interiority become interwoven, and communicated to his academic audiences through combinations of transcripts and images. This, as for art therapy, using reenactment as a route to 
accessing, or creating ways to articulate and comprehend otherwise unexpressed feelings and embodied and affective experiences is particularly pertinent to researching everyday life. The ways people feel about the everyday tasks they perform - such as laundry - are also part of their experiences and sentiments of their situatedness in social, gendered, generational and material contexts of home. These are areas of life where such feelings are expressed in ways that are usually 'invisible' from the views of others, through the tasks that people do not usually (need to actively) 'think' about.

The video tours and re-enactments described above are already connected to arts practice in that they were inspired by the observational documentary practice that informs ethnographic filmmaking. They invite participants to reflect on their everyday feelings and experiences, things they have usually never talked about before and that are often done alone. In doing so they also forge a correspondence between the experience of being a research participant and therapeutic processes - which was commented on by participants in earlier research (Pink 2004b). As for art therapy practice, video reenactments and explorations with participants have enabled them to reflect on their self-identities in ways that tend to be self-defining and, if not transformative in a therapeutic sense, give participants a medium in which to express ways of doing and being that $d o$ assert a definition of self, but normally with no audience. It also sometimes inspired them to comment on how they were situated in relation to persons and institutions, when performing everyday cleaning tasks in ways that affirmed their identities as resistant to those of the 'housewife' (Pink 2004a). There, like phototherapy practice Martin writes of these reenactments brought to the fore how the personal is interwoven in the wider material, sensorial, social and political contexts of everyday life. They offer a route through which we might come to know and understand how aspects of everyday life that are mundane, routine, hidden, personal yet often politically and institutionally framed, and ultimately meaningful in ways that often remain invisible yet are fundamental to the ongoing ways in which we live. Thus even in these mundane everyday life circumstances reenactments can be seen as sites that have the potential for personal self-awareness.

In our work on energy use, video recorded laundry reenactments likewise showed us how participants distinguished their own practices from those of others, often but not exclusively so through generational distinctions. For example, in one household laundry duties were shared by the mother and grandmother, and each spent some time re-enacting their routines to us. In doing so, they emphasised idiosyncrasies in how they 
do the laundry, which personalised laundry chores and distinguished ways of doing things not only from each other but also in relation to institutional entities. For instance, Brenda showed Kerstin how she went beyond the advice of soap manufacturers by always putting 'that little bit extra' into detergent measuring cups, because 'when you've got a full load, sometimes that little bit doesn't always seem as if there's enough to kind of wash through', adding that 'it's just me being extravagant'. Brenda routinely did this despite her previous assertion that the load, which mainly contains darks from school uniforms and work trousers, was not actually 'drenched in dirt'. It ended up in the laundry because, usually, her daughter preferred items to be washed after use, even if only worn or handled briefly. Brenda followed this rule and ensures cleanliness by adding additional detergent but also subverted the process; 'because these aren't really that dirty'. To do this she choose a shorter wash cycle (39 minutes) at a lower temperature (30 degrees). This also allowed her to put in a new wash before heading out to work, thus ensuring she made best use of her time. However, the 30-degree cycle was different from the one she used for whites. The latter would go on at 40 degrees and for longer, so as to 'keep them whiter and lighter'. Brenda and her daughter's understanding of loads also differed in that Brenda sometimes left larger gaps at the top of the drum, to allow items to move around and for water and detergent to flow between them. To her daughter, this was wasteful, not because she was worried about energy but because the family of six had purposefully purchased a larger machine to keep up with the huge amounts of washing they created.

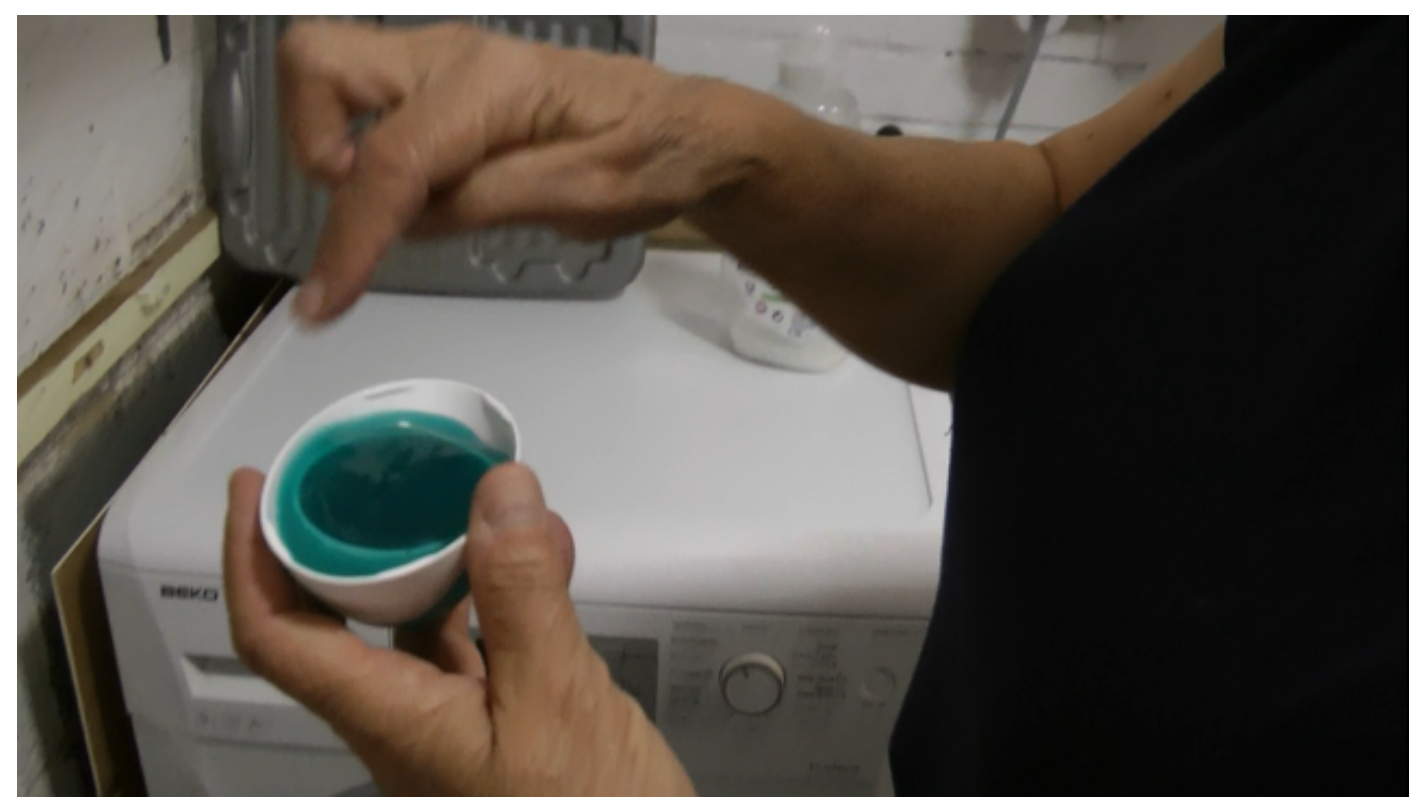




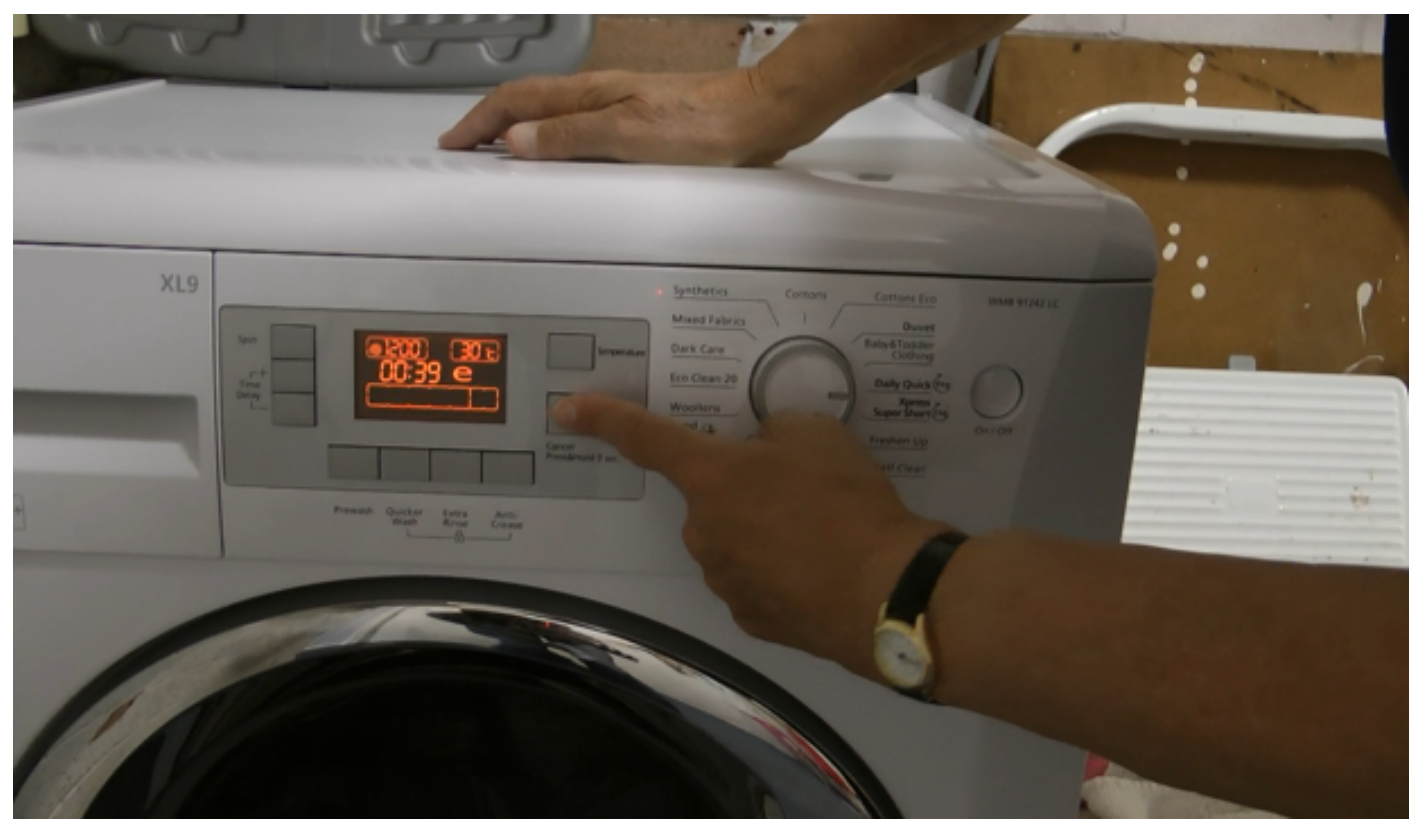

Figure 3. Screenshots: Brenda's measure of detergent and her preferred machine setting. (C)

LEEDR, Loughborough University.

Being there, seeing, smelling and feeling what Brenda and her daughter talked about meant that Kerstin could test her own understandings of the laundry process and probe further for clarification. The knowledge that emerged was thus derived from interplay between reenactment, observation and participant and researcher reflection. This interplay fostered contexts for participants to demonstrate their personal involvement, learned and embodied expert knowledge and, if less confident or less particular about the way they do their washing, to similarly demonstrate the latter through their reenactment.

Another example where personal identity and sensory and embodied knowledge were entangled and asserted through laundry practices referred to ironing. Ironing played an important role in Brenda and her daughter's laundry routines; both enjoyed ironing and considered it relaxing, almost 'therapeutic' (their words), often combining it with listening to music or catching up with TV programmes. As Brenda explained, her daughter was particularly good at quickly and skillfully working through large quantities of ironing. In contrast, Jane tried to 'get away' with as little ironing as possible. As she pegged up laundry on the washing line outside, she recounted that it was her job as a child to iron the family's washing on a Sunday morning: 'everybody's clothes had to be ironed, before midday, or the world would stop spinning on its axis ... And everything 
was ironed - sheets, underwear, towels - which is just barmy!' Since running her own household, Jane had reduced ironing, even more so since the birth of her children, which has increased the sheer volume of washing. There are certain things Jane would not iron, such as sheets and underwear, pyjamas and sports clothes, that is, anything either hidden from public view or used in contexts where a 'scruffier' look was acceptable. With other items Jane employed a number of strategies to limit ironing to the absolute necessary, such as buying non-iron shirts for her husband and to untangle wet laundry and 'almost shake out some of the creases, really, before you put it on the line'.
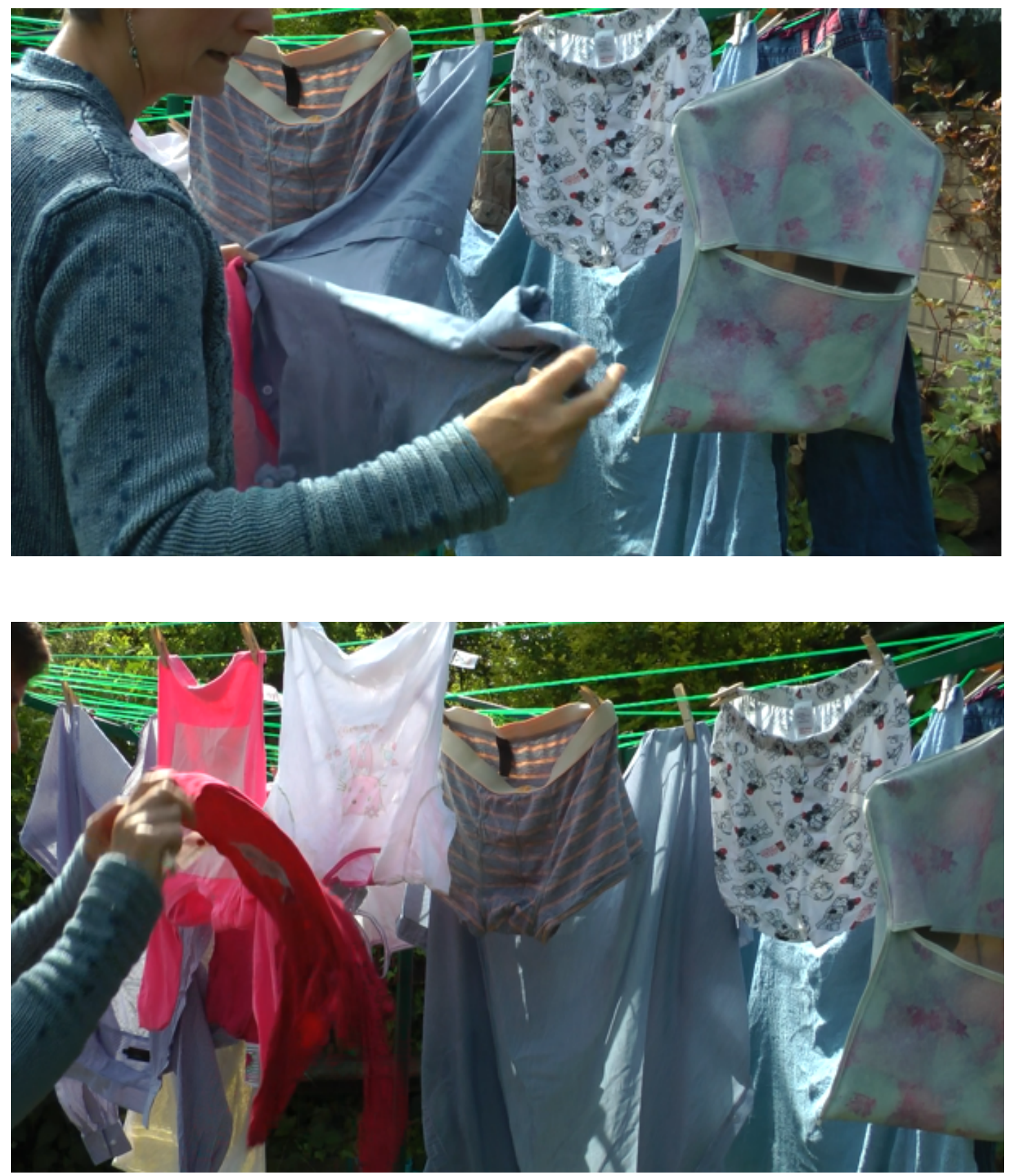
Figure 4. Screenshot. Jane shakes and disentangles laundry to reduce creases. C LEEDR, Loughborough University.

Later, on the living room sofa, she showed Kerstin how she turned and folded laundry and sorted items into piles to go straight into family members' wardrobes or on a separate ironing pile. As she explained, 'if something's maybe a bit creased but a little bit kind of fitted, then I'd often not iron it, cos I know that $[. .$.$] your body heat will drop$ the creases'. The fact that Jane's mother apparently disapproved of her selective ironing practices demonstrates that the latter can be understood both as pragmatic choices and as part of experiencing and accomplishing the self through the performance (or nonperformance) of everyday tasks.

In these reenactments are also collaborative processes, whether they are developed in ethnography or therapeutic contexts, and they engage visual practices and lens-based media as part of their process. Yet we also need to question the status of the knowledge or ways of knowing that they produce so that we can explore how reenactments are related to everyday realities, how everyday mundane activities are embodied and emplaced, and how the everyday is both a site for personal and individual transformation through the therapeutic process and of/for everyday improvisation.

\section{Exploring the relationship between experience and representation}

One way in which to interpret reenactments is to consider them to be bringing to the fore embodied 'memory'. Yet memory cannot be understood as separate from imagination, and indeed can be understood as a form of imagination (Pink 2009), in ways similar to Keightly and Pickering's (2012: 204) notion of 'menomic imagination', which is related to what they refer to as 'declarative or reflexive remembering'. However, to understand embodied, unspoken, affective and experiential forms of everyday knowing as they are reenacted as well as being reflected on, the idea of memory as a self-conscious practice of imagining does not fully answer the question.

The reenactments described above might be understood as representing certain understandings of what is normally done, made in collaboration between researcher and participant. Following this line of thought we can indeed interpret the participants' performances of their laundry as bringing to the fore resistant or alternative identities to those actually presented to them by others or as part understandings of normative practices, as the 'right' way to do laundry. The arts practice of phototherapy offers one 
explanation: following Martin, we could understand video reenactments of domestic tasks as offering the opportunity for researcher and participant to collaboratively create new and critical representations. This suggests reenactments-as-representations are not necessarily of what is already there, and thus do not necessarily stand for what is remembered or already exists. Instead they enable participants to create ways of imagining their self-identities and everyday practices, in which participant reflexivity comes to the fore, and which leads to a way of understanding what it is about laundry that matters to people. Anthropological understandings of art can also aid us in this: as Ingold argues, 'Perhaps it is the very notion of the image that has to be rethought, away from the idea that images represent, on another plane, the forms of things in the world ...' (Ingold 2010: 16). Thus reenactments as performative representations that happen in the context of how and where they are 'normally' performed cannot actually represent something they are separate from, but at part of the very thing that they are developed to represent. Therefore such representations are not for seeing data in: Ingold rhetorically asks 'Are drawings or paintings of things in the world, or are they like things in the world, in the sense that we have to find our ways through and among them, inhabiting them as we do the world itself?' (Ingold 2010: 16). Following this, representations, whether reenactments themselves or video recordings of them, are for moving with, they are part of the routes we take as we move forward through the world, and create new ways of knowing for both participants and researchers (see Pink 2013). However, if participant's performances (representations) of tasks and video representations of their reenactments of everyday tasks can only be taken to stand for the tasks themselves in that they both are the tasks and are representations of them, this raises the question of how we might interpret them in terms of offering useful research knowledge. As we noted at the beginning of this article, we are seeking to learn about the flow of everyday life, to access it in situ rather than to capture a slice of it. Yet we need to be able to discuss our findings in a form that can be represented. What, therefore can video reenactments be said to stand for?

To address this final question we turn to another intersection where the study of arts practice - in the form of how art is both made and seen - comes together with the neurosciences. Barbara Stafford's discussions of what she refers to as the 'enactive or neurophenomenological accounting of the intelligence lodged in the body (that is, in visual, kinaesthetic, haptic, acoustic, olfactory, and visceral sensations)' (2010:1) suggests a way forward. Stafford is interested in what the brain sciences and the arts can 
tell each other and her proposals invite us to consider new ways to approach questions around representations and the enactment of routine and embodied ways of knowing. She points out that the question of how representations, such as 'dance, music, architecture, sculpture, painting, film, performance, installation, and Web art' signify 'through some kind of bodily action' was not only the subject matter of phenomenologists such as Husserl and Merleau-Ponty, but also she notes 'Enaction continues to be relevant to research on the embodied, embedded, and distributed aspects of cognition' (2010: 5). If, we apply Stafford's analysis of arts practice - of embodied performances as artistic 'representations' - to embodied reenactments as performances of everyday life activities, this invites us to ask how the body and mind are implicated in the performance of everyday tasks, and what an reenactment can tell us about this. The work of the neuroanthropologist Greg Downey offers a possible explanation. Downey has approached the neurosciences to understand performance in his work on the bananeira na cabeça technique in Brazilian capoeira, whereby practitioners learn to balance, land or spin on the head (Downey 2012: 77). Treating this as an exaggerated example, Downey argues that it shows how 'the acquisition of skill necessarily entails physiological, neurological, and psychological transformation' (2012: 77).

The laundry reenactments created a context in which such forms of enskillment came to the fore as much as they do in performances of arts practice. Laura, Brenda and Jane's laundry reenactments reveal some of the ways in which participants in our research engaged with, impacted on and adapted to the qualities of materials through the laundry process. This is most evident in participants' aims and abilities to transform the sensory and material qualities of laundry items to achieve specific results, for instance to change their smell, remove dirt or reduce creases. Simultaneously, however, the very accomplishment of tasks was often acted out as satisfying and self-asserting in itself as participants varyingly described the sense of achievement and well-being that comes with working one's way through the laundry basket or following items as they transform. Notably, when asked how they make decisions about laundry loads and settings, participants often referred to knowing based on 'experience'. This commonsensical category of experience both connoted the long-term everyday engagement with a task and the processes of trial and error that were recounted to us (e.g. shrinkage, detergent residue). It also encompassed the bodily forms of knowing that participants employed automatically, and to which they regularly adapted. For example, the felt weight of laundry items and loads. Participants knew and showed us how heavy 
a wash load could be to not cause any problems during the washing or drying process. This was not weighed by measurement but through the body, by sensing the volume of laundry in one's arms, the washing basket, or the drum. While turning to biological metaphors does not place any greater claim to have got to the (scientific) truth, in this conceptualization remembering and imagining are not simply ways of reflexively contemplating something that exist as separate from the individual. Rather, they might also be seen as ways of consciously and verbally enacting something that is neurologically and biologically part of them and their bodies. That is, in Downey's (2012) terms, something they are physically, behaviourally and perceptually adapted to.

In the case of reenactment as a research method, we are thus dealing with a performance that bridges the gap between representation and action. It involves doing, imagining and representing and thus invites us to ask questions about what it is then that we are seeking to access about the doing of the activity through its reenactment, and why this is possible. A turn to critical art historical and anthropological renderings of the neurosciences offers ways to understand how what people actually do becomes invested into biological residues, and to understand what they show us as both bearing that imprint but moreover changing it as part of what Stafford calls 'The brain's sheer ongoingness' (2010: 45), since, she argues, 'Our mental capacities and processes are ... inextricably linked to the organism's continuous and dynamic interaction with the environment' (2010: 45). These scholars, who bridge the divide between social science, arts and brain sciences, inform our understanding of the potential of re-enactment techniques in ethnographic practice. They demonstrate a need to account for reenactments as not about simply remembering something that one does, or imagining what normal everyday life is like, but as expressive ways of drawing on embodied resources and ways of knowing that are precisely part of who participants are, psychologically and physiologically.

\section{Conclusions}

Insights from art therapy practice and art historical reflections on neuroscience offer new ways to understand the relationship between representations and embodied experiences. While contemporary theories of practice (e.g. Warde 2005) focus away from the individual, , as both ethnographic and art therapy research continues to show (see Hogan and Pink 2012) we still need to account for how individual subjectivity and agency (Pink 2012). A focus on reenactment and performance, shared by ethnographic and art therapy 
practice and understood at a nexus between art history, anthropology and the neurosciences offers a novel way to configure the relationship between practical activity in the world, and the idea of human subjectivity, resistance and agency. Indeed it is here, in the reenactment - or in the reenacting body and self - that we can begin to unpack how the relationship between the individual, the environment and activity are intertwined.

\section{Acknowledgments}

The interdisciplinary LEEDR project, based at Loughborough University, is jointly funded by the UK Research Councils' Digital Economy and Energy programs (grant number EP/I000267/1). For further information about the project, collaborating research groups and industrial partners, please visit www.leedr-project.co.uk. The authors would like to thank all the households who have generously participated in this research. In the context of this article, we are especially grateful to Laura, Brenda and Jane who reviewed our accounts of their re-enactments.

\section{References}

Downey, G. (2011) 'Learning the "Banana-Tree": Self Modification through Movement' in T. Ingold (ed) Redrawing Anthropology, Ashgate

Gardiner, M. (2009) 'Book Review: Philosophizing the Everyday: Revolutionary Praxis and the Fate of Cultural Theory, John Roberts (2006). London: Pluto. ISBN 0745324-11-8. Everyday Life: Theories and Practices From Surrealism to the Present, Michael Sheringham (2006). Oxford, UK: Oxford University Press. ISBN 0-199273-95-2' Space and Culture 12(3):383-388.

Hogan, S. (2012) (ed) Revisiting Feminist Approaches to Art Therapy. Oxford: Berghahn.

Hogan, S. and S. Pink, (2012) 'Visualising Interior Worlds: Interdisciplinary Routes to Knowing' in Pink, S. (ed) Advances in Visual Methodology, London: Sage, pp230-247.

Ingold, T. (2010) Ways of mind-walking: reading, writing, painting, Visual Studies, $25: 1,15-23$

Ingold, T. (2011) 'Worlds of sense and sensing the world: a response to Sarah Pink and David Howes' in Social Anthropology/Anthropologie Sociale 19(3): 313-317 
Irving, A. 2010 Dangerous Substances and Visible Evidence: Tears, Blood, Alcohol, Pills. Visual Studies 25(1):24-35

Lammer, C. (2012) 'Healing Mirrors: Body Arts and Ethnographic Methodologies' in S. Pink (ed) Advances in Visual Methodology, London: Sage

Martin, R. (2009) 'Inhabiting the image: photography, therapy and re-enactment phototherapy' European Journal of Psychotherapy and Counselling Vol. 11, No. $1,35-49$

McCalman, I., and Paul A. Pickering (2010) Historical Reenactment: From Realism to the Affective Turn, Palgrave MacMillan

O’Neill, M. (2012) 'Ethno-Mimesis and Participatory Arts' in S. Pink (ed) Advances in Visual Methodology, London: Sage

Parkin, S. and R. Coomber 2009 Value in the Visual: On Public Injecting, Visual Methods and their Potential for Informing Policy (and Change). Methodological Innovations Online 4(2): 21-36

Pink, S. (2004a) Home Truths: gender, domestic objects and everyday life, Oxford: Berg.

Pink, S. (2004b) 'Performance, self-representation and narrative: Interviewing with video' in C. Pole (ed) Seeing is Believing? Approaches to visual research Studies in Qualitative Methodology - Volume 7, Elseiver Science, pp61-77.

Pink, S. (2009) Doing Sensory Ethnography, London: Sage

Pink, S. (2012) Situating Everyday Life: Practices and Places, London: Sage.

Pink, S. (2013) Doing Visual Ethnography. Revised and expanded $3^{\text {rd }}$ edition, London: Sage

Pink, S. and K. Leder Mackley (2013) 'Saturated and Situated: rethinking media in everyday life' Media, Culture and Society

Sherwin, Richard K., N. Feigenson and C. Spiesel (2007): What Is Visual Knowledge, and What Is It Good For? Potential Ethnographic Lessons from the Field of Legal Practice, Visual Anthropology: Published in cooperation with the Commission on Visual Anthropology, 20:2-3, 143-178

Sheringham, M. (2006) Everyday Life: Theories And Practices from Surrealism to the Present, Oxford: Oxford University Press

Stafford, B. M. (2010) A Field Guide to a New Metafield: Bridging the HumanitiesNeurosciences Divide. University of Chicago Press 
Thrift, N. (2008) Non-Representational Theory: Space, Politics, Affect, London: Routledge.

Warde, Alan. 2005. Consumption and theories of practice. Journal of Consumer Culture 5, no. 2: 131-153. 